\title{
Platinum-based chemotherapy for recurrent CNS tumours in young patients
}

\author{
E Douek, J E Kingston, J S Malpas, P N Plowman
}

\begin{abstract}
Twenty nine patients (median age 12 years) with a CNS tumour, received platinum-based chemotherapy for assessable disease. In 23 patients there was an objective response with improvement lasting for a median duration of 11 months. There was little difference in the response to cisplatinum or carboplatin therapy. The response rates in specific disease groups were: medulloblastoma $8 / 10$, two with a complete response (CR) and six with a partial response (PR); ependymoma 1/5 PR; pineal retinoblastoma 5/5 with three $C R$ and two PR; primitive neurectodermal tumours (PNET) 2/2 PR and pineal germ cell tumours $6 / 6$ with four $C R$ and two $P R$. It is concluded that platinum-based chemotherapy has a beneficial effect on CNS tumours of the CNS, especially medulloblastoma, ectopic intracranial retino-blastoma and pineal germ cell tumours.
\end{abstract}

Central nervous system tumours are the commonest solid tumours seen in children under the age of 15 years and account for approximately $25 \%$ of childhood cancer deaths. ${ }^{1}$ Adjuvant chemotherapy has led to modest improvements in survival for children with a medulloblastoma, ${ }^{2}$ and there is particular interest in the response to chemotherapy of intracranial germ cell tumours. ${ }^{3}$

Several workers have reported platinum derivatives to be effective in both primary and metastatic brain tumours in childhood. ${ }^{4-8}$ However, a cure with chemotherapy is rare in patients with an incompletely resected tumour or one recurrent after surgery/radiotherapy.

This paper describes our 29 patients with a CNS tumour who were treated with platinum-based chemotherapy.

\section{Table 1 Details of patients}

\begin{tabular}{|c|c|}
\hline $\begin{array}{l}\text { No of patients reviewed } \\
\text { Sex Male } \\
\quad \text { Female } \\
\text { Under } 15 \text { years (median } 6 \cdot 1)(2 \cdot 2-14 \cdot 6) \\
\text { Over } 15 \text { years (median } 19 \cdot 7)(15 \cdot 5-32)\end{array}$ & $\begin{array}{l}29 \\
17 \\
12 \\
17 \\
12\end{array}$ \\
\hline $\begin{array}{l}\text { Histological Classification } \\
\text { Medulloblastoma } \\
\text { Ependymoma } \\
\text { Ectopic intracranial retinoblastoma } \\
\text { Primitive neurectodermal tumours (PNET) } \\
\text { Pineal astrocytoma } \\
\text { Pineal germ cell tumour }\end{array}$ & $\begin{array}{r}10 \\
5 \\
5 \\
2 \\
1 \\
6\end{array}$ \\
\hline
\end{tabular}

Patients and methods

Twenty nine children and young adults who were treated at St Bartholomew's hospital during a seven year period were reviewed (table 1). All had malignant disease that could be evaluated. Staging evaluation was performed at the time of entry into the study and included CT head scanning, myelography, CSF studies and bone marrow aspiration. The median age of the patients was 12 years (range $2-32$ ). The male to female ratio was $1 \cdot 4: 1$.

Before chemotherapy, all patients had normal renal function and satisfactory haematological findings-with absolute neutrophil count $>1000 / \mathrm{ml}$ and platelet count $>100000 / \mathrm{ml}$. The patients were regularly monitored for gastrointestinal, haematological, renal and neurological toxicity. The patients were treated with either cisplatinum or carboplatin and combinations of other chemotherapeutic agents (tables 2 and 3). When cisplatinum was used, aggressive prehydration and mannitol enforced diuresis was used. Hydration therapy was also given after carboplatin.

RESPONSE DETERMINATION

Response was determined clinically and objectively after two chemotherapy courses. If stable disease or an objective response was established, further courses of platinum-based chemotherapy were administered, up to a maximum of six until progression of the tumour or unacceptable toxicity occurred. Standard response criteria, as used by several workers in previous studies, ${ }^{4-8}$ were applied to measure the extent of the disease (table 4).

The response was assessed by CT scan after two courses of chemotherapy. The duration of response was defined as the interval from the first dose of platinum to the time to progression or unacceptable toxicity, with at least one course being administered. The dose of steroid also had to be decreased over a six week period to designate either a CR or PR. Recurrence was suggested by clinical deterioration and confirmed by increase in the size of the tumour or presence of new lesions on CT scan.

Table 2 Chemotherapy regimens

\begin{tabular}{lll}
\hline & $\begin{array}{l}\text { Cisplatinum } \\
\text { (12 patients) }\end{array}$ & $\begin{array}{l}\text { Carboplatin } \\
\text { (17 patients) }\end{array}$ \\
\hline VCR/CCNU & $3(4)$ & $1(4)$ \\
VCR/Etoposide & $2(2)$ & $15(4)$ \\
VCR/Etoposide/Cyclo & $4(3)$ & - \\
Bleomycin/Etoposide & $3(4)$ & - \\
Single agent platinum & - & $1(1)$ \\
\hline (The number in brackets is the mean number of courses given)
\end{tabular}


Table 3 Dosages

\begin{tabular}{lll}
\hline Vincristine & $1.5 \mathrm{mg} / \mathrm{m}^{2}$ & IV $\times 1$ \\
Cisplatinum & $60 \mathrm{mg} / \mathrm{m}^{2}$ & IV $\times 1$ \\
Carboplatin & $200 \mathrm{mg} / \mathrm{m}^{2}$ & IV $\times 3$ \\
CCNU & $100 \mathrm{mg} / \mathrm{m}^{2}$ & PO $\times 3$ \\
Etoposide & $100 \mathrm{mg} / \mathrm{m}^{2}$ & IV $\times 3$ \\
Bleomycin & $12-40 \mathrm{mg} / \mathrm{m}^{2}$ & IV $\times 1$ \\
\hline
\end{tabular}

The platinum dose was reduced by $33 \%$ if the total neutrophil count has been $<1000 / \mathrm{ml}$ or a platelet count $<50000 / \mathrm{ml}$ during a previous course and if necessary the frequency of courses was decreased.

\section{Results}

Of the 29 patients, two received only one course of chemotherapy because of rapid clinical deterioration. Nine patients achieved a CR, 13 a PR, whilst one had stable and six had progressive disease (table 5). Only six patients had no radiotherapy and, of the remaining 23 patients, 20 had irradiation after two courses of chemotherapy and were given further chemotherapy post-irradiation. The duration of response ranged from 2-48 months (mean 11). The subsequent radiotherapy may have increased the response duration, but response rates recorded here are for chemotherapy. In general, patients with a positive response showed clinical improvement before evidence of response on CT scan. Response criteria were applied to patients before radiotherapy was given. CR was observed in nine patients after four to six courses whilst a PR was seen in 13 patients after two to six courses (median 3 ). Significant improvement in most responders occurred after two courses (figs 1 and 2). There was no difference in duration of response between the two platinum derivatives, but there were differences in toxicity, which are discussed below. There was a higher response rate in patients with a medulloblastoma, a pineal germ
Table 4 Response criteria

1 Complete response (CR) Complete disappearance of tumour on CT scan ( 1 month minimum), with stable, improved or normal neurological examination

$2 \quad$ Partial response (PR) $\quad \begin{aligned} & >50 \% \text { decrease in tumour } \\ & \text { mass with stable or improved } \\ & \text { neurological examination. } \\ & \text { (Product of } 2 \text { diameters) }\end{aligned}$

2 Partial response (PR) $\quad \begin{aligned} & >50 \% \text { decrease in tumour } \\ & \text { mass with stable or improved } \\ & \text { neurological examination. } \\ & \text { (Product of } 2 \text { diameters) }\end{aligned}$

2 Partial response (PR) $\quad \begin{aligned} & >50 \% \text { decrease in tumou } \\ & \text { mass with stable or improved } \\ & \text { neurological examination. } \\ & \text { (Product of } 2 \text { diameters) }\end{aligned}$

3 Marginal response (MR) Unequivocal but less than $50 \%$ decrease in tumour mass

4 Stable disease (SD) No significant change on CT scan but stable or improving neurological examination

5 Progressive disease (PD) Increase in tumour mass on CT scan with or without neurological deterioration

cell tumour and/or an ectopic intracranial retinoblastoma but a low response rate in patients with ependymoma. Overall, the mean duration of response was similar in the most responsive histological groups. Only 14/29 $(50 \%)$ patients are still alive.

\section{TOXICITY}

In general the toxicity encountered was tolerable. All patients experienced mild/moderate gastrointestinal upset (Grade 1-2) ${ }^{6}$ which could usually be controlled with sedative and anti-emetic therapy. Myelosuppression was tolerable though three patients had problems with thrombocytopaenia necessitating a reduction in carboplatin dosage and prolongation of interval between courses of therapy. There were no serious infectious complications and no significant persistent renal toxicity. However, two patients required a reduction of their cisplatinum dose in view of a fall in glomerular filtration rate (Grade 2 50-75\% normal). ${ }^{6}$
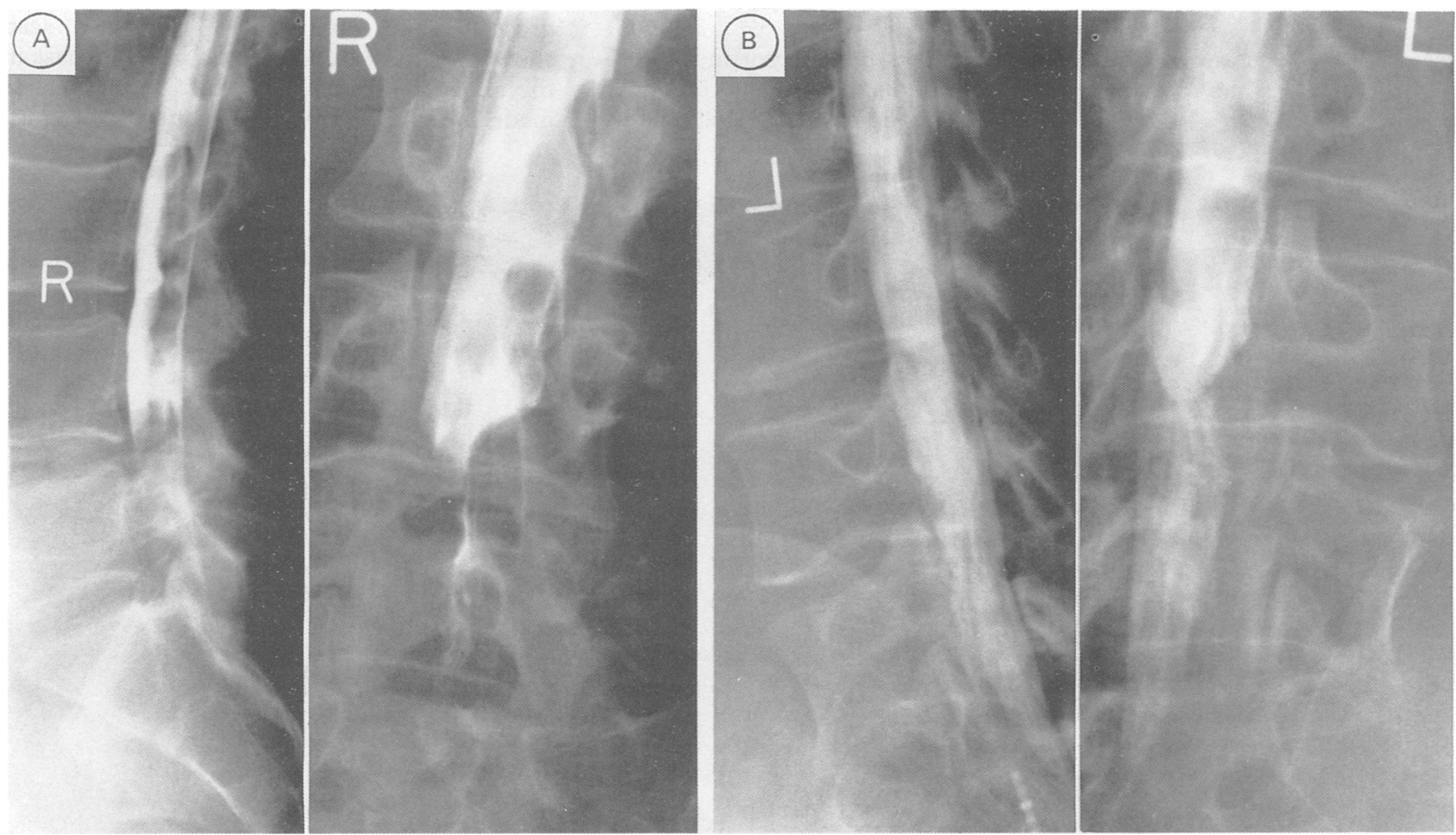

Figure 1 Initial myelogram $\left(A_{1} B_{1}\right)$ shows disseminated medulloblastoma with multiple filling defects and partial block at L4/L5. After three courses of VCR/Etoposide/Carboplatin, the repeat films $\left(A_{2} B_{2}\right)$ show a decrease in the number of filling defects and improved flow of contrast medium. 
Table 5 Response designations

\begin{tabular}{lcccccc}
\hline & $\begin{array}{l}\text { No of } \\
\text { Histology }\end{array}$ & $C R$ & $P R$ & $S D$ & $P D$ & $\begin{array}{l}\text { Mean } \\
\text { duration of } \\
\text { response }\end{array}$ \\
\hline Medulloblastoma & 10 & 2 & $6(2)$ & - & 2 & 14 \\
Ependymoma & 5 & - & 1 & 1 & $3(2)$ & 13 \\
Pineal Germ Cell Tumour & 6 & 4 & $2(1)$ & - & - & 16 \\
Pineal Astrocytoma & 1 & - & -2 & - & - & 6 \\
Ectopic Intracranial Retinoblastoma & 5 & 3 & 2 & - & - & 17 \\
PNET (primitive neurectodermal tumour) & 2 & - & 13 & 1 & 6 & 11.0 \\
Totals & 29 & 9 & 13 & &
\end{tabular}

Overall Response Rate $23 / 29$ patients.

(Number in brackets indicates those not receiving radiotherapy) Response to chemotherapy was always assessed before subsequent radiotherapy.

Cisplatinum was discontinued after four courses in two patients who developed moderate audiotoxicity (high frequency hearing loss). Interestingly, two patients suffered exacerbation of fits, one of whom also had hyponatraemia with inappropriate $\mathrm{ADH}$ secretion after her first course of vincristine, etoposide and carboplatin. Further chemotherapy in these patients was not possible. Treatment was also discontinued in one girl, with a pineal germ cell tumour, who had respiratory complications which were thought to be related to bleomycin administration. In total five patients discontinued treatment, six patients had to have their dose decreased as a result of either haematological or renal toxicity.

\section{Discussion}

Cytotoxic levels of platinum are reached in the CSF within a short period after infusion into patients with a CNS tumour. ${ }^{11-13} \mathrm{Khan}$, et $a l^{4}$ reported a favourable response of recurrent brain tumours to platinum products and several others have documented similar results. ${ }^{5-8}$ Our review also confirms that certain CNS tumours respond to platinum-based chemotherapy.

These observations may be pertinent to the management of infants with such a tumour, in whom there is a strong case for initial chemo- therapy and delayed radiotherapy. ${ }^{14}$ Chemotherapy may also enhance the effects of radiotherapy or reduce the size of the tumour before surgery. Nephrotoxicity is well documented with platinum products and the potential enhancement of ototoxicity with radiotherapy ${ }^{910} \mathrm{can}$ lead to marked hearing problems and the need to limit doses. Allen, et $a l^{7}$ have shown carboplatin to be effective with less risk of renal and ototoxicity. In our review there were no significant septic haematological complications but neurological complications could be severe. One should be wary of treating patients who have had seizures because there is the risk of increasing intracranial pressure and cerebral herniation during chemotherapy.

Our numbers are small and therefore we cannot comment on whether patients who received radiotherapy had a greater magnitude of response and a longer overall duration of response. However, as seen in table 5 all patients in the complete response group had had radiotherapy. Germ cell tumours of the CNS appear to be very responsive. This was illustrated in one adult who presented with weight loss, anorexia and gynaecomastia and he was found to have Parinaud's syndrome and a grossly raised HCG level. CT head scan showed a pineal tumour and a midline mass in the anterior recess of the third ventricle. $\mathrm{He}$ made a rapid complete response to chemo-
Figure 2 Initial scan shows disseminated retinoblastoma with large pineal mass and hydrocephalus. Repeat scan after $V C R$

Etoposide/Carboplatin some nine months later shows marked resolution.
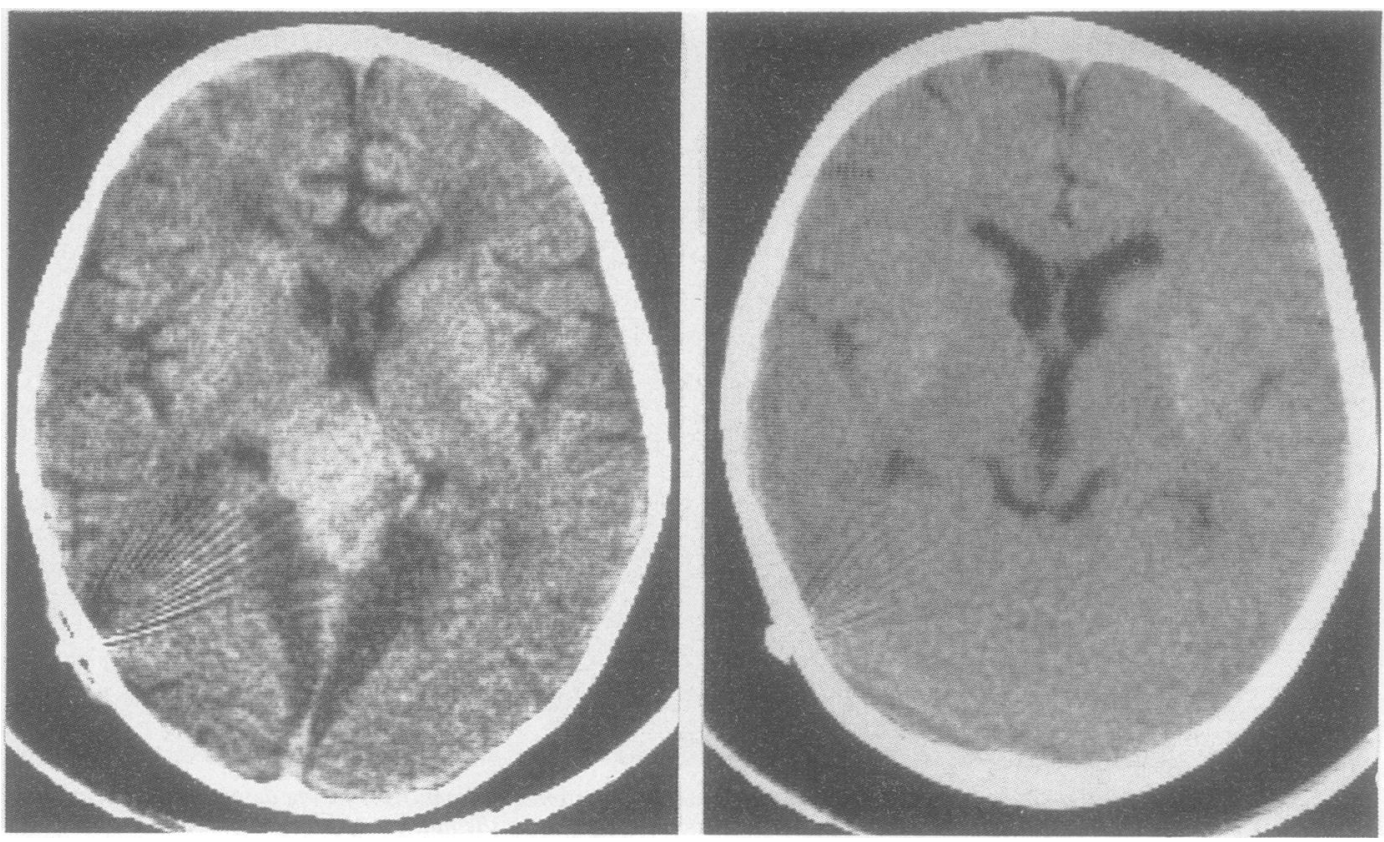
therapy. Some workers state that chemotherapy is the preferred treatment of primary or metastatic non-seminomatous germ cell tumours of the brain. ${ }^{315}$ There are also reports of secondaries from shunt procedures and these should be easily treated if in a responsive histological group. ${ }^{1617}$

The therapeutic value of cisplatinum and carboplatin must be balanced against the risks of significant and irreversible toxicity. Carboplatin may be preferable where the inner ear is in the field of radiation, although following whole neuraxis radiotherapy reduction in red marrow tolerance may limit its use. This problem may later be resolved using growth factors. Carboplatin may induce responses in cisplatinum resistant disease.

As others have reported, ependymomas are poorly responsive compared to medulloblastoma, pineal germ cell tumours, PNET and ectopic retinoblastoma. Our response rate in medulloblastoma is similar to that reported by Walker and Allen. ${ }^{8}$ Platinum products should therefore be considered in the management of both primary and selected recurrent CNS tumours in childhood and further studies of pre-radiation platinum-based chemotherapy are currently in progress.

ED, JEK and JSM gratefully acknowledge support of the Imperial Cancer Research Fund. We thank Professor M Besser, Endocrinology Department, St Bartholomew's Hospital, for his permission to include one of his patients, and $S$ Howarth for typing the manuscript.

1 Young JL Jr, Ries LG, Silverberg E, Horm J, Miller R Cancer incidence, survival and mortality for children younger than age 15 years. Cancer 1986;58:598-602.
2 Allen J, Bloom J, Extel I, et al. Brain tumours in children: Current co-operative and institutional chemotherapy trials in newly diagnosed and recurrent disease. Seminars in Oncology 1986;13:110-122. (CCSG/S10P)

3 Rustin G, Newlands E, Bagshawe K, Begent R. Successfu management of metastatic and primary germ cell tumours in the brain. Cancer 1986;57(11):2108-13.

4 Khan A, D'Souza B, Wharam M, et al. Cisplatin therapy in recurrent childhood brain tumours. Cancer Treat Report 1982;66(12):2013-20.

5 Diez B, Marges J, Muriel F, et al. Evaluation of cisplatin in children with recurrent brain tumours. Cancer Treat Reports 1985;69(7):911-13.

6 Sexauer C, Khan A, Burger P, et al. Cisplatin in recurrent paediatric brain tumours. A POG Phase II study. Cancer paediatric brain tumour

7 Allen J, Walker R, Luks E, et al. Carboplatin and recurrent childhood brain tumours. $J$ Clin Oncology 1987;5(3): 459-63.

8 Walker R, Allen J. Cisplatin in the treatment of recurrent childhood primary brain tumours. J Clin Oncology 1988 6(1):62-6.

9 Kirkbride P, Plowman P. Platinum chemotherapy and the inner ear: implications for "standard" radiation portals. Br J Radiol 1989;62(737):457-62.

10 Walker D, Pillow J, Waters K, Kier D, et al. Enhanced cisplatinum ototoxicity in children with brain tumours who have received simultaneous or prior cranial irradiation. Medical and Paediatric Oncology 1989;17:48-52.

11 Walker R, Cairncross J, Posner JB, et al. Acute neurological deterioration after cisplatin therapy for primary and metastatic brain tumours. Proc ASCO 1986;5:135.

12 DeGregorio $M$, King O, Holleran W, et al. Ultra filtrate and total platinum in plasma and cerebrospinal fluid in a patient with neuroblastoma. Cancer Treatment Reports 1985;69(12):1441-2.

13 DeGregorio M, Wilbur B, King O, et al. Peak cerebrospinal fluid platinum levels in a patient with Ependymoma: Evaluation of two different methods of cisplatin administration. Cancer Treatment Reports 1986;70(12):1437-8.

14 Loeffler J, Lavally B, et al. Pre-radiation chemotherapy for infants and poor prognosis children with medulloblas-
toma. Int J Radiation Oncol Biol Phys 1988;15(1):177-81.

15 Rustin G, Newlands E, Begent R, et al. Weekly alternating etoposide, methrotrexate and actinomycin/vincristine and cyclophosphamide chemotherapy for the treatment of cyclophosphamide chemotherapy for the treatment of
CNS metastases of choriocarinoma. J Clinical Oncology CNS metastases

16 Kun L, Tang T, Sty J, Camitta B. Primary cerebral germinoma and ventriculoperitoneal shunt metastases. Cancer 1981;48:213-16.

17 Kleinman G, Hochberg F, Richardson E, et al. Systemic metastases from medulloblastoma cancer. Cancer 1984;48: 2296-309. 